\title{
A MATHEMATICAL MODEL TO ANALYZE THE STATIC STABILITY OF HYBRID (AERO-HYDRODYNAMICALLY SUPPORTED) VEHICLES
}

\author{
M Collu, M H Patel, F Trarieux, Cranfield University, UK
}

PRESENTED AT THE 8TH SYMPOSIUM ON HIGH SPEED MARINE VEHICLE, 21-23 MAY 2008, NAPLES

\section{SUMMARY}

Among the new concepts developed for high speed marine vehicles over the last two decades [1], the 'aerodynamic alleviation' [2] approach consists in using an aerodynamic surface to 'alleviate' the weight sustained by the hydrodynamic lift. Such vehicle experiences aerodynamic and hydrodynamic forces of the same order of magnitude, therefore the dynamic models developed for airborne and waterborne vehicles are not suitable.

Considering a vehicle having a high-speed prismatic planing hull and one or more aerodynamic surfaces, the authors propose two mathematical methods. The first one calculates the equilibrium attitude of the vehicle at a given speed and its numerical implementation has been used to undertake a parametric analysis of the influence of some configuration characteristics on performances. The second method analyzes the static stability of the HV. Starting from the dynamic analysis previously proposed by the authors [3], the characteristic polynomial of the HV dynamics is derived and a static stability criterion is proposed.

\section{NOMENCLATURE}

a

[A]

$\mathrm{a}_{\mathrm{ah}}$

$\mathrm{a}_{\mathrm{ws}}$

$\mathrm{A}_{\mathrm{ij}}$

$\mathrm{AC}_{\mathrm{i}}$

[B]

$\mathrm{B}_{\mathrm{ij}}$

c

$\mathrm{c}_{\mathrm{L}, \mathrm{ai}}$

$\mathrm{c}_{\mathrm{D}, \mathrm{ai}}$

$\mathrm{c}_{\mathrm{m}, \mathrm{ai}}$

[C]

$\mathrm{C}_{\mathrm{ij}}$

CG

[D]

$\mathrm{D}_{\text {ah }}$

$\mathrm{D}_{\mathrm{ai}}$

$\mathrm{D}_{\mathrm{F}}$

$\mathrm{D}_{\mathrm{i} 0}$

$\mathrm{D}_{\mathrm{ws}}$

$\mathrm{F}_{\mathrm{i}}$

HV

$\mathrm{L}_{\mathrm{ai}}$

$\operatorname{lcg}$ surface surface

moment pitch moment arm of $\mathrm{D}_{\mathrm{F}}$

aero- and hydrodynamic added mass matrix

pitch moment arm of $D_{a h}$

pitch moment arm of $D_{w s}$

$\partial F_{i} / \partial \ddot{\eta}_{j}(\mathrm{~kg}),(\mathrm{kg} \mathrm{m})$

aerodynamic center of ith-aerofoil

aero- and hydrodynamic damping matrix

$\partial F_{i} / \partial \eta_{j}\left(\mathrm{~kg} \mathrm{~s}^{-1}\right),\left(\mathrm{kg} \mathrm{s}^{-1} \mathrm{~m}\right)$

pitch moment arm of $\mathrm{N}$

Lift coefficient of the i-th aerodynamic

Drag coefficient of the i-th aerodynamic

Pitch moment coefficient of the i-th

aerodynamic surface

hydrodynamic restoring matrix

$$
\partial F_{i} / \partial \eta_{j}\left(\mathrm{~kg} \mathrm{~s}^{-2}\right),\left(\mathrm{kg} \mathrm{s}^{-2} \mathrm{~m}\right)
$$

center of gravity

aerodynamic WIGe matrix

planing hull aerodynamic drag

i-th surface aerodynamic drag

hydrodynamic friction drag

$\partial F_{i} / \partial \eta_{0}\left(\mathrm{~kg} \mathrm{~s}^{-2}\right),\left(\mathrm{kg} \mathrm{s}^{-2} \mathrm{~m}\right)$

hydrodynamic whisker spray drag

surge $(i=1)$, heave $(i=3)$ force or pitch $(i=5)$

Hybrid Vehicle

i-th surface aerodynamic lift

CG longitudinal position, from transom $\mathrm{m} \quad$ mass of the $\mathrm{HV}$ at equilibrium $(\mathrm{kg})$

$\mathrm{M}_{\mathrm{ai}} \quad$ i-th surface aerodynamic moment

mac $_{a i}$ mean aerodynamic chord of the $\mathrm{i}$-th aerofoil

$\mathrm{N}$ hydrodynamic potential force $(\mathrm{N})$

$\mathrm{R} / \mathrm{W}$ total resistance-to-weight ratio

RULM Rectilinear Uniform Level Motion

$\mathrm{S}_{\mathrm{ai}} \quad$ Reference area of the i-th aerodynamic surface

$\mathrm{T}$ thrust force (N)

TP thrust force point of action

$\mathrm{V}_{0} \quad$ velocity at equilibrium state $\left(\mathrm{m} \mathrm{s}^{-1}\right)$

vcg CG vertical position, from the keel

W weight of the vehicle $(\mathrm{N})$

WIGe Wing In Ground effect

wrt with respect to

$\beta \quad \quad$ deadrise angle of the planing hull angle between the direction of $\mathrm{T}$ and the keel coordinate of the i-th point in the body-fixed axes system, $z$ axis

height above the surface, pos. upward (m) surge displacement (m)

heave displacement, positive downward (m) pitch rotation, positive bow up (rad)

$\partial \eta_{i} / \partial t$

$\partial^{2} \eta_{i} /(\partial t)^{2}$

angle between the $\mathrm{i}$-th wing mac and the keel density $\left(\mathrm{kg} \mathrm{m}^{-3}\right)$, $\rho^{\mathrm{a}}$ air, $\rho^{\mathrm{h}}$ seawater trim angle (deg), angle between the keel of the planing hull and the waterline coordinate of the $\mathrm{i}$-th point in the body-fixed axes system, $x$ axis 


\section{INTRODUCTION}

The hybrid vehicle (HV) configuration analyzed here is composed by a high speed prismatic planing hull and one or more wings. In particular, being at low height above the surface, the wing experiences the 'wing in ground effect (WIGe)', a positive effect that influence the lift, drag and moment. Therefore, in order to develop a model which studies the dynamic of the HV, research on dynamic models of prismatic planing hull and WIGe vehicles has been carried out.

\subsection{WING IN GROUND EFFECT VEHICLES}

Research on WIGe vehicles has mainly been carried out in the former Soviet Union, where they were known as 'Ekranoplans'. The Central Hydrofoil Design Bureau, under the guidance of R. E. Alekseev, developed several test craft and the first line production ekranoplans: Orlyonok and Lun types [4]. In the meantime, several research programs were undertaken in the west to better understand the peculiar dynamics of the vehicles flying in ground effect. Irodov [5] and Rozhdestvensky [6] [7] made important contributions to the development of WIGe vehicles dynamic models. In the 60's and the 70's, Kumar [8], [9] started research in this area in Cranfield University. He carried out several experiments and studied the stability issues of a vehicle flying in ground effect. Staufenbiel [10] in the 80 s carried out an extensive work on the influence of the aerodynamic surface characteristics on the longitudinal stability in wing in ground effect. $\mathrm{He}$ obtained experimental data with the WIGe vehicle $\mathrm{X}-114$ built by Rhein-Flugzeugbau in Germany in the 70 's. The equations of motion for a vehicle flying IGE were defined, including non linear effects. In the USA, Gera [11] used the Staufenbiel's work to investigate the stability of a Russian ekranoplan, using the available data for the F-104 aircraft, a vehicle with an aerodynamic layout similar to the Russian vehicle. The approach is similar to that used for conventional airplane, even if the model is not so accurate (changes of stability derivatives with height not taken into account). Hall [12], in 1994, extended the work of Kumar, modifying the equations of motion of the vehicle flying in ground effect, taking into account the influence of perturbations in pitch on the height above the surface.

\subsection{PLANING CRAFT}

Research on high speed planing started in the early twentieth century for the design of seaplanes. Later, the research focused on applications to design planing boats and hydrofoil crafts. During the period 1960 to
1990, many experiments have been carried out and new theoretical formulations proposed. Savitsky [13] carried out an extensive experimental program on prismatic planing hulls and developed a mathematical method to estimate the equilibrium attitude of a planing craft. Martin [14] derived a set of equations of motion for the surge, pitch and heave degrees of freedom and demonstrated that surge can be decoupled from heave and pitch motion. The model of Savitsky is still under development, as showed by a recent article of Savitsky, DeLorme and Datla [15]. It is still one of the reference methods used for the preliminary design of planing craft.

\section{3 'HYBRID VEHICLES' CONCEPT}

In 1976, Shipps [16] analyzed a new kind of race boats, known as 'tunnel hull' race boats. The advantages of this new configuration come from the aerodynamic lift. In 1978, Ward et al. [17] published an article on the design and performance of a ram wing planing craft: the KUDU II. This vehicle, which consists in two planing sponsons separated by a wing section, was able to run at $78 \mathrm{kts}$ (almost $145 \mathrm{~km} / \mathrm{h}$ ), thanks to the aerodynamic lift alleviation. In 1978, Kallio [18] performed comparative tests between the KUDU II and the KAAMA. The KAAMA is a conventional mono hull planing craft. The data obtained during comparative trials showed that the KUDU II pitch motion, in sea state 2, at about 40 to 60 knots, was about $30 \%$ to $60 \%$ lower than the conventional planing hull KAAMA. In 1997, Doctors [2] proposed a new configuration called 'Ekranocat' for which he mentioned the 'aerodynamic alleviation concept'. The weight of the catamaran was alleviated by aerodynamic lift, thanks to a more streamlined superstructure than in traditional catamarans. The theoretical analysis and computed results showed that a reduction in the total drag of around $50 \%$ can be obtained at very high speed. Russell [19] developed an analysis of aerodynamic and hydrodynamic forces and moments acting on tunnel race boat. This approach is tailored only to the race tunnel boat, therefore cannot be used to design and evaluate a different configuration.

In the following references [16][17][18] some experimental data, theoretical and computed results on vehicles which can be classified as 'HV' are presented, but none of them presents an analysis of the static stability of a vehicle having both hydrodynamic and aerodynamic surfaces. 


\section{AXIS SYSTEM}

In this work the same axis systems proposed by the author in [3] will be used. Briefly they are: one earthaxis system and two body-axis system, right-handed and orthogonal.

\subsection{EARTH-AXIS SYSTEM $(x \mathrm{O} z)$}

The directions of the axis are fixed in space. The $z$-axis is oriented vertically downward; the $x$-axis forwards and parallel to the undisturbed waterline and the origin is fixed at the undisturbed waterline level.

\subsection{BODY AXIS SYSTEMS}

The origin $\mathrm{O}$ is coincident with the CG of the HV. The $x$ and $z$ axis lay in the longitudinal plane of symmetry, $x$ positive forward and $z$ positive downward. Two systems are used:

- aero-hydrodynamic axes $\left(\eta_{1} \mathrm{O} \eta_{3}\right)$, the $x$-axis being parallel to the steady forward velocity $\mathrm{V}_{0}$,

- $\quad$ geometric axes $(\xi \mathrm{O} \varsigma)$, the $x$-axis $\xi$ being parallel to the keel of the planing hull.

Aero-hydrodynamic axes are the counterpart of the aerodynamic axes (called also wind or body-wind axes (UK) or stability axes (US) used for airplanes.

\section{CONFIGURATION}

The general configuration used to represent the HV has to be intended as modular. The elements presented are all the possible elements that can be taken into account in this analysis:

- a high-speed prismatic planing hull (hydrodynamic surface), with constant deadrise angle $\beta$,

- one or more airfoils (aerodynamic surfaces),

- an aero- or hydro-propulsion system.

This analysis focuses on the high speed equilibrium state, but the HV is supposed to have waterborne capability at rest. Hydrodynamic and aerodynamic surfaces can be fitted with control systems, but this work is limited to a control-fixed analysis.

\section{EQUILIBRIUM STATE CALCULATION}

This work analyses the static stability of a HV configuration. The stability analysis starts from an equilibrium state and studies how the vehicle reacts after a disturbance. The static stability studies how it reacts immediately after the disturbance whereas the dynamic stability studies if and how the vehicle, eventually, returns back to the initial equilibrium state.

The author proposes a mathematical method that can calculate the equilibrium attitude of the $\mathrm{HV}$, starting from geometric, inertial, aerodynamic and hydrodynamic characteristics of the vehicle.

\subsection{HYPOTHESES}

The present work concentrates on the analysis of an equilibrium state characterized by a rectilinear trajectory, a constant speed and a constant altitude above the surface, which will be referred as Rectilinear Uniform Level Motion (RULM). The vehicle is supposed to be always in contact with the water, and in a calm water situation. Waves are not taken into account.

\subsection{FORCES AND MOMENTS}

The forces and moments acting on the vehicle are illustrated in Figure 2. They can be divided in four groups:

- gravitational (weight, W),

- $\quad$ thrust (propulsion force, $\mathrm{T}$ ),

- aerodynamic (lift, drag and moment from the $1^{\text {st }}$ and $2^{\text {nd }}$ aerodynamic surface, $\mathrm{L}_{\mathrm{a} i}, \mathrm{D}_{\mathrm{ai}}, \mathrm{M}_{\mathrm{ai}}$ and aerodynamic drag of the hull above the surface, $\mathrm{D}_{\mathrm{ah}}$,

- hydrodynamic (potential force, N, frictional force, $\mathrm{D}_{\mathrm{F}}$, whisker spray drag, $\mathrm{D}_{\mathrm{ws}}$ ).

\section{7.a) Gravitational force}

Since the equilibrium motion analyzed is a level motion, the height above the surface is constant; therefore the direction of the velocity at equilibrium is normal to the weight direction. The weight (W) acts at the center of gravity $(\mathrm{CG})$, which is also the origin of the body-fixed axis system. The coordinates of the $\mathrm{CG}$ are $(0,0)$.

\section{7.b) Power force}

The thrust can be provided by an aero-propulsion system or a hydro-propulsion system. The thrust acts at the thrust point (TP), in a direction determined by the angle $\varepsilon$, the angle between the direction of the thrust and the keel, positive for an anticlockwise movement (view from the starboard side of the vehicle). 


\section{7.c) Aerodynamic forces}

Aerodynamic forces can be divided in two groups: forces acting on aerofoils and force acting on the portion of the hull above the water.

The aerodynamic force acting at the center of pressure of the aerofoil, in the longitudinal plane, is usually represented with an equivalent system of two forces and one moment acting at the aerodynamic center of the aerofoil (AC): lift (L), defined as perpendicular to the velocity, drag (D), defined as parallel to the velocity, and a pitch moment (M), positive for a bow up movement.

$$
\begin{aligned}
& L_{i}=\frac{1}{2} \rho_{a} V_{0}^{2} S_{a i} c_{L, a i} \\
& D_{i}=\frac{1}{2} \rho_{a} V_{0}^{2} S_{a i} c_{D, a i} \\
& M_{i}=\frac{1}{2} \rho_{a} V_{0}^{2} S_{a i} c_{m, a i} m a c_{a i}
\end{aligned}
$$

Usually the aerodynamic coefficients $\mathrm{c}_{\mathrm{L}, \mathrm{a}}, \mathrm{c}_{\mathrm{D}, \mathrm{ai}}$ and $\mathrm{c}_{\mathrm{m}, \mathrm{a}}$, are functions only of the angle of attack, but in this analysis, also the influence of the height above the surface has to be taken into account. The angle of attack is the sum of the trim angle and $\eta_{\mathrm{ai}}$, which is the angle between the chord of the wing and the keel of the hull. The height above the surface to evaluate the aerodynamic coefficients is that of the aerodynamic center.

The dry section of the hull experiences an aerodynamic drag force $\left(D_{\text {ah }}\right)$. To evaluate its contribution, Savitsky [15] proposes the expression:

$$
D_{a h}=\frac{1}{2} \rho^{a} V_{0}^{2} A_{h} c_{D, a h}
$$

where

- $\mathrm{A}_{\mathrm{h}}$ is the frontal area of the planing hull,

- $\mathrm{C}_{\mathrm{D}, \mathrm{ah}}$ is the aerodynamic drag coefficient of the hull (approximated as 0.70).

Since it is not known where the hull aerodynamic drag acts, $D_{a h}$ is supposed to be acting on the CG. Therefore no moment is generated by this force.

\section{7.d) Hydrodynamic forces}

Referring to the work developed by Savitsky et al. from 1964 through 2007 [13], [15], the hydrodynamic forces are:

- potential force $\mathrm{N}$,

- friction force $\mathrm{D}_{\mathrm{F}}$,

- whisker spray drag $D_{w s}$.

The potential force direction is supposed to be normal to the keel and acting at the hydrodynamic center HC. The friction force acts parallel to the keel line, halfheight between the keel and the chine line. The whisker spray drag $D_{w s h a s}$ been analyzed in particular in [15]. Also $D_{w}$ sis assumed to act through the CG of the HV.

\subsection{SYSTEM OF EQUATIONS OF EQUILIBRIUM}

Once all the forces and moments are known, a system of equations of equilibrium can be developed. The vehicle, in the longitudinal plane, has three degrees of freedom, and a system of three equations of equilibrium is needed. The system is:

- $\quad$ surge equation: sum of the vertical forces $=0$,

- heave equation: sum of horizontal forces $=0$,

- $\quad$ pitch equation: sum of pitch moments $=0$.

The CG of the HV has been chosen to be the point of reference for the moments.

\section{8.a) Surge Equation}

It states that the sum of the aerodynamic drags, the component of potential and friction hydrodynamic forces parallel to the velocity, and the whisker spray drag has to be equal to the component of the thrust parallel to the velocity.

$$
\begin{aligned}
& -D_{a 1}-D_{a 2}-D_{a h}+ \\
& -N \sin (\tau)-D_{F} \cos (\tau)-D_{W S}+ \\
& +T \cos (\tau+\varepsilon)=0
\end{aligned}
$$

\section{8.b) Heave Equation}

The sum of aerodynamic lift, vertical components of the potential and friction hydrodynamic force and the vertical component of the thrust has to be equal to the weight of the HV: 


$$
\begin{aligned}
& L_{a 1}+L_{a 2}+N \cos (\tau)-D_{F} \sin (\tau)+ \\
& -W+T \sin (\tau+\varepsilon)=0
\end{aligned}
$$

\section{8.c) Pitch Moment Equation}

The sum of the aerodynamic moments, hydrodynamic moments and the moment generated by the thrust force has to be equal to zero.

$L_{a 1}\left[\xi_{A C 1} \cos (\tau)+\zeta_{A C 1} \sin (\tau)\right]+$

$+D_{a 1}\left[\xi_{A C 1} \cos (\tau)+\zeta_{A C 1} \sin (\tau)\right]+M_{a 1}+$

$+L_{a 2}\left[\xi_{A C 2} \cos (\tau)+\zeta_{A C 2} \sin (\tau)\right]+$

$+D_{a 2}\left[\xi_{A C 2} \cos (\tau)+\zeta_{A C 2} \sin (\tau)\right]+M_{a 2}+$

$D_{a h} a_{a h}+D_{w s} a_{w s}-N \cdot c-D_{F} \cdot a+$

$T\left[\xi_{T P} \sin (\varepsilon)+\zeta_{T P} \cos (\varepsilon)\right]=0$

with the conditions

$a_{a h}=a_{w s}=0$

\subsection{SOLUTION OF THE EQUATIONS OF EQUILIBRIUM}

The method to solve the system of the three equations of equilibrium is a modified version of the 'Savitsky long-form method' illustrated in [20].

In the Savitsky method, the weight is sustained by hydrostatic and hydrodynamic forces, while in this work the weight is sustained by both aerodynamic and hydrostatic-hydrodynamic forces. Obviously, as it can be seen in equations $(0),(0)$ and $(0)$, the aerodynamic drag and moments also have to be taken into account.

In the Savitsky method, the trim angle is not known at the start, therefore a trim angle has to be assumed and, through a cycle, the right trim angle that fulfill equations $(0),(0)$ and $(0)$ is eventually found.

In this work an additional assumption has to be taken, since the aerodynamic forces depend on:

- trim angle $(\tau)$ (the angle of attack is the sum of the trim angle $\tau$ and the angle between the mac and the keel $\eta$ ),

- $\quad$ height above the surface.

This leads to a trim angle $(\tau)$ cycle nested into the height above the surface (h) cycle, as illustrated in Figure 3. Assuming a value for the height above the surface of the CG $\left(\mathrm{h}_{\mathrm{i}}\right)$ and a trim angle $\tau_{\mathrm{i}}$, the aerodynamic forces can be calculated. Then the weight sustained by the hydrodynamic forces is equal to the difference between the total weight and the sum of the aerodynamic lifts. At this point the 'long-form method' of Savitsky can be followed, taking into account also aerodynamic drags and moments, and the equilibrium trim angle can be derived. The height above the surface of the vehicle $h_{i+1}$ can then be calculated. If this $h_{i+1}$ is equal to the $h_{i}$ assumed, then the equilibrium attitude of the vehicle has been found. If not, a new $h$ cycle is performed.

1.9.a) Validation of the mathematical model

As far as the authors are aware, no experimental data on HV trials are available in the public domain, but the model proposed can analyze also planing craft configurations.

Analyzing the configuration B of Table 1, the comparison between the data obtained by the authors and the results presented in [15] are presented in Figure 4. The data are in good agreement through the whole speed range, both for the trim angle and for the resistance to weight ratio.

\section{STATIC STABILITY}

Analyzing the forces and moments under the small disturbances hypothesis, the static stability of the HV is derived using the Routh-Hurwitz criterion.

\subsection{ROUTH-HURWITZ CRITERION}

In general, given a polynomial equation in $\mathrm{s}$,

$$
A_{n} s^{n}+A_{n-1} s^{n-1}+\ldots+A_{1} s+A_{0}=0
$$

the Routh-Hurwitz method determines how many roots will have positive real parts. If the polynomial equation is the characteristic polynomial of the dynamics of a vehicle, this method can be used to determine the stability of the vehicle. In fact, if all the roots have a negative real part, the system is stable, statically and dynamically.

Furthermore, Staufenbiel [10] showed how the last coefficient of the polynomial $\left(\mathrm{A}_{0}\right)$ can be used to determine the static stability of the system. If the condition

$$
A_{0} / A_{n}>0
$$


is fulfilled, then the system can be considered statically stable.

\subsection{HV CHARACTERISTIC POLYNOMIAL AND STATIC STABILITY CONDITION}

In [3], the authors developed a mathematical model to study the longitudinal dynamics of the HV. A system of ordinary differential equations of motion was derived for the longitudinal plane in the frame of smalldisturbance stability theory. The same mathematical model has been adopted for this work.

\subsection{1.a) Complete Order System}

By defining a state space vector $\underline{v}$ as:

$\underline{v}=\left[\begin{array}{llllll}\eta_{1} & \eta_{3} & \eta_{5} & \eta_{3} & \eta_{5} & \eta_{0}\end{array}\right]$

the system of equations of motion can be rearranged in the Cauchy standard form (or state-space form). The characteristic polynomial of the complete order system can be derived:

$$
\begin{aligned}
& A_{6} s^{6}+A_{5} s^{5}+A_{4} s^{4}+A_{3} s^{3}+ \\
& +A_{2} s^{2}+A_{1} s+A_{0}=0
\end{aligned}
$$

With $A_{6}=1$, the static stability is assured when

$$
A_{0}=n u m_{0} / \Delta>0
$$

where num $_{0}$ is equal to

$$
V_{0}\left[D_{10}\left(B_{31} C_{53}-B_{51} C_{33}\right)-B_{11}\left(C_{35} D_{50}-C_{53} D_{30}\right)\right]
$$

and $\Delta$ is equal to

$$
\begin{aligned}
& \left.\left(I_{55}+A_{55}\right)\right)\left(m^{2}+m\left(A_{11}+A_{33}\right)+A_{11} A_{33}-A_{31} A_{13}\right]+ \\
& -\left(m+A_{11}\right) A_{53} A_{35}-\left(m+A_{33}\right) A_{51} A_{15}+ \\
& +A_{53} A_{31} A_{15}+A_{51} A_{13} A_{35}
\end{aligned}
$$

\subsection{1.b) Reduced Order System}

This mathematical method requires to be validated against experimental data. Unfortunately, no experimental data on the static stability of a $\mathrm{HV}$ configuration is available in the public domain.
To plan such experiments, it is necessary to have a physical insight of the condition stated in equation (0). This condition, applied to the complete order system $(0)$, is relatively complex. Assuming that the surge degree of freedom $\left(\eta_{1}\right)$ can be decoupled from heave $\left(\eta_{3}\right)$ and $\left(\eta_{5}\right)$ pitch degrees of freedom, a simplified version of the condition ( 0 ) can be obtained, leading to a better physical insight.

In [3] the author derived a mathematical model of the dynamics of the HV starting from the systems of equations of motion of WIGe vehicles and planing craft. As regard the dynamics of a planing craft, Martin [14] demonstrated that the surge motion can be decoupled from the heave and pitch motion. For the dynamics of WIGe vehicles, Rozhdestvensky [6] proposed a reduced order system where the surge motion is decoupled from heave and pitch motion. This hypothesis has been confirmed by, among others, Delhaye [21].

By defining the reduced order state space vector $\underline{v}$ as

$\underline{v}=\left[\begin{array}{lllll}\eta_{3} & \eta_{5} & \eta_{3} & \eta_{5} & \eta_{0}\end{array}\right]$

the Cauchy standard form (or state-space form) of the reduced order system is obtained. The characteristic polynomial can be derived:

$$
A_{5} s^{5}+A_{4} s^{4}+A_{3} s^{3}+A_{2} s^{2}+A_{1} s+A_{0}=0
$$

With $A_{5}=1$, the static stability is assured when

$$
A_{0}=\frac{V_{0}\left(C_{33} D_{50}-C_{53} D_{30}\right)}{\left(A_{55}+I_{55}\right)\left(m+A_{33}\right)-A_{53} A_{35}}>0
$$

\subsection{REDUCED ORDER STATIC STABILITY: PHYSICAL INSIGHT}

Each coefficient in equation $(0)$ is the derivative with respect to:

- $\quad$ accelerations $\left(\mathrm{A}_{\mathrm{ij}}\right)$,

- heave position $\left(\mathrm{C}_{\mathrm{ij}}\right)$

- $\quad$ height above the surface $\left(\mathrm{D}_{\mathrm{ij}}\right)$

of the sum of aerodynamic and hydrodynamic forces (and moments). Referring to [3], remembering that the superscript ' $a$ ' stands for aerodynamic and ' $h$ ' for hydrodynamic and that $\mathrm{Z}$ is the heave force (positive 
downward) and $\mathrm{M}$ the pitch moment (positive bow up), the coefficients are equal to:

$$
\begin{aligned}
& A_{33}=A_{33}^{a}+A_{33}^{h}=-Z_{\eta^{\prime} 3}^{a}-Z_{\eta^{\prime} 3}^{h} \\
& A_{35}=A_{35}^{a}+A_{35}^{h}=-Z_{\ddot{\eta} 5}^{a}-Z_{\ddot{\eta} 5}^{h} \\
& A_{53}=A_{53}^{a}+A_{53}^{h}=-M_{\ddot{\eta} 3}^{a}-M_{\eta ं 3}^{h} \\
& A_{55}=A_{55}^{a}+A_{55}^{h}=-M_{\ddot{\eta} 5}^{a}-M_{\eta ் 5}^{h}
\end{aligned}
$$

$C_{33}=C_{33}^{h}=-Z_{\eta 3}^{h}, C_{33}^{a}=0$

$C_{53}=C_{53}^{h}=-M_{\eta 3}^{h}, C_{53}^{a}=0$

$D_{30}=D_{30}^{a}=-Z_{\eta 0}^{a}, D_{30}^{h}=0$

$D_{50}=D_{50}^{a}=-M_{\eta 0}^{a}, D_{50}^{h}=0$

The aerodynamic derivatives can be estimated with, for example, [21][22] and the hydrodynamic derivatives with the approaches presented in [14] or [23]. Using these expressions for the configuration presented in section 1.5 we have

$$
\left(A_{55}+I_{55}\right)\left(m+A_{33}\right)-A_{53} A_{35}>0
$$

Therefore the static stability condition of the reduced order becomes

$$
\frac{D_{50}}{D_{30}}-\frac{C_{53}}{C_{33}}>0
$$

\subsection{2.a) Similarity with WIGe vehicles}

A parallel with WIGe vehicles static stability criteria is illustrated. The static stability condition derived by Staufenbiel [10] and Irodov [5] is:

$$
M_{w} / Z_{w}-M_{h} / Z_{h}<0
$$

where $M_{w}$ and $M_{h}$ are the derivatives of pitch moment with respect to the heave velocity and the height above the surface, $Z_{\mathrm{w}}$ and $Z_{h}$ are the heave force same derivatives $\left(\mathrm{M}_{\mathrm{h}} / \mathrm{Z}_{\mathrm{h}}\right.$ is the same as $\left.\mathrm{D}_{50} / \mathrm{D}_{30}\right) . \mathrm{M}_{\mathrm{w}} / \mathrm{Z}_{\mathrm{w}}$ is defined also as the aerodynamic center of pitch and $\mathrm{M}_{\mathrm{h}}$ / $\mathrm{Z}_{\mathrm{h}}$ as the aerodynamic center in height. Remembering positive abscissa means ahead the CG, the condition (0) can be expressed as in [7]: "the (aerodynamic) center in height should be located upstream of the (aerodynamic) center in pitch"

Dividing the lift due to a variation of the pitch angle ( $\left.\mathrm{L}_{\text {alpha }}\right)$ from the lift due to a variation of the height above the surface $\left(\mathrm{L}_{\text {height }}\right)$, condition (0) states the point of action of force $\mathrm{L}_{\text {height }}$ should be located upstream the point of action of force $\mathrm{L}_{\text {alpha }}$.

1.12.b) HV Static Stability Criterion (reduced order)

For the HV, using the expressions (0), the static stability condition $\frac{D_{50}}{D_{30}}-\frac{C_{53}}{C_{33}}>0(0)$ is:

$M_{\eta 0}^{a} / Z_{\eta 0}^{a}-M_{\eta 3}^{h} / Z_{\eta 3}^{h}>0$

The first term $\mathrm{M}_{{ }_{\eta 0} 0}^{\mathrm{a}} / \mathrm{Z}^{\mathrm{a}}{ }_{\eta 0}$ is the analogue of the aerodynamic center in height of WIGe vehicles. The author proposes for the second term the name 'hydrodynamic center in heave', so that the condition (0) can be also expressed as:

"the hydrodynamic center in heave should be located downstream of the aerodynamic center in height"

As before, dividing the hydrodynamic lift due to a heave variation $\left(\mathrm{L}_{\mathrm{hyd}}\right)$ from the lift due to a variation of the height above the surface $\left(\mathrm{L}_{\text {height }}\right)$, the point of action of $\mathrm{L}_{\text {height }}$ should be located upstream the point of action of $\mathrm{L}_{\text {hyd. }}$.

\section{PARAMETRIC ANALYSIS}

A parametric analysis is required in the preliminary design phase of a new vehicle. Using the method illustrated in section 1.9, the influence of some configuration parameters on the resistance to weight ratio $(\mathrm{R} / \mathrm{W})$ of the $\mathrm{HV}$ is investigated.

The Resistance-to-Weight ratio is defined as:

$$
R / W=\frac{\text { Aer } . \text { Drag }+ \text { Hyd.Drag }}{\text { Weight }}
$$

\subsection{PARAMETERS}

Considering the hybrid configuration of the HV, many parameters have to be taken into account (Figure 1). The aerodynamic surfaces parameters are:

- aerodynamic profile type,

- mean aerodynamic chord (mac),

- $\quad$ surface area, 
- $\quad$ angle between the keel and the mac $(\eta)$,

- $\quad$ position of the wing relative to the hull.

The profile shape determines the aerodynamic coefficients; therefore the choice of the profile is very important. The investigation of the optimum profile for a given configuration is beyond the scope of this work, since it requires a thorough analysis of the available profiles and CFD simulations. The author has chosen a modified Glenn Martin 21 section. This profile has a very poor efficiency (lift-to-drag ratio), but it has been adopted only to have experimental validated values, presented in [24]. The influence of the length of the mean aerodynamic chord (and the surface area) has been analyzed in section 1.13.a, the influence of $\eta$ in section 1.13.b.

As regard the planing hull the parameters are:

- beam length,

- $\quad$ deadrise angle $\beta$.

To have a direct comparison with a planing craft configuration (no wing), one of the configurations tested by Savitsky in [15] has been adopted: its characteristics are presented in Table 1, Case B. Its beam and deadrise angle have been used also for the $\mathrm{HV}$ configurations of these analysis.

Some important characteristics of the vehicle are also:

- mass,

- longitudinal position of the $\mathrm{CG}$,

- vertical position of the $\mathrm{CG}$.

The mass of the vehicle in all the analysis has been kept constant: the author supposes that the aerodynamic surface or surfaces can be exploited to, for example, carry part of the fuel (like airplanes) or other systems of the vehicle.

The vertical position of the vehicle has been kept fixed, since its position is designed to fulfill the hydrostatic stability criteria. An analysis of the influence of the longitudinal position of the $\mathrm{CG}(\mathrm{lcg})$ is presented.

\subsection{3.a) Wing surface area analysis}

Three configurations have been analyzed: A, B and C. They are identical unless for the mac length:

- $\quad$ config. $\mathrm{B}, \mathrm{mac}=0$ meter (no wing)

- config. $\mathrm{A}, \mathrm{mac}=14.14$ meters,
- config. $\mathrm{C}, \mathrm{mac}=20$ meters.

In Figure 5, the resistance to weight ratio curves of the three configurations are presented. The speed range can be divided in two zones by the speed at which the curves cross each other (about Froude number 2.9, 40 knots), called $\mathrm{V}_{\mathrm{X}}$. In the speed range $\mathrm{V}_{0}<\mathrm{V}_{\mathrm{X}}$, the total drag of $\mathrm{B}$ (planing craft) is lower than the total resistance of $A$ and $C$. For $V_{0}>V_{X}$, the $H V$ with wing experiences less drag.

This is because at low speed the hydrodynamic forces experienced by the HV and the planing craft are almost the same, since the aerodynamic forces are still low compared to hydrodynamic forces. Nonetheless the aerodynamic forces lead to an increase of the trim angle, therefore the horizontal component of the hydrodynamic potential force (hydrodynamic potential drag) acting on the $\mathrm{HV}$ is bigger (in module) than the same component acting on the HV without any wing. The vehicle with wing/s experiences a higher hydrodynamic drag.

As the speed increases, the aerodynamic forces grow and the required hydrodynamic lift force becomes lower and lower and, at the same time, the hydrodynamic drag diminishes. Therefore, also if the trim angle of the HV with wing is still bigger than the trim angle of the $\mathrm{HV}$ without wing, at a certain speed the total drag experienced by the HV with wing is lower than the total drag experienced by the $\mathrm{HV}$ without wing.

If the requirement of the vehicle is to reach a speed $\mathrm{V}>\mathrm{V}_{\mathrm{x}}$, the configurations with wing will require a power propulsion lower than the planing craft. Remembering that the profile used has a low efficiency, with a more efficient profile the speed $V_{X}$ can be lowered and the power propulsion can be further reduced.

1.13.b) Angle between the mac and the keel ( $\eta$ ) analysis

The configurations analyzed are A, D and E. In order:

- $\eta_{\mathrm{D}}=0$ degrees,

- $\eta_{\mathrm{E}}=5$ degrees,

- $\eta_{\mathrm{A}}=10$ degrees.

The resistance to weight ratio of the three configurations is presented in Figure 6. The curves are similar to that of Figure 5. This is because the aerodynamic lift is increased both if the mac length (wing area) is increased and if the angle of attack is 
increased (augmenting $\eta$ the angle of attack is augmented). Therefore the same physical insight proposed for the analysis of section 1.13.b applies here. The behavior is less accentuated because, while in Figure 5 there is a configuration without wing, in this analysis all the three configurations have a wing.

\subsection{3.c) Longitudinal position of the $\mathrm{CG}(\mathrm{lcg})$ analysis}

The configurations analyzed are A, F and $\mathrm{G}$ and the resistance to weight ratio is represented in Figure 7.

- $\operatorname{lcg}_{\mathrm{F}}=\operatorname{lcg}_{\mathrm{A}} * 0.85(-15 \%)$,

- $\operatorname{lcg}_{\mathrm{A}}=8.656$ meters,

- $\operatorname{lcg}_{\mathrm{G}}=\operatorname{lcg}_{\mathrm{A}} * 1.15(+15 \%)$.

In order to keep the position of the aerodynamic center fixed, the coordinates have been changed accordingly ( since the point of origin is the $\mathrm{CG}$ ).

As it can be seen, lcg seems to have the strongest influence on the performance of the HV. The position of the CG strongly influences the trim angle of the HV, and a rearward shift of the $C G$ leads, at equal speed, to a bigger trim angle variation than the increase of the wing area or the increase of angle $\eta$. Comparing the trim angle of configuration $\mathrm{A}$ with configuration $\mathrm{F}$ :

- $\quad \mathrm{Fn}_{\mathrm{B}}=1, \tau_{\mathrm{F}}=\tau_{\mathrm{A}}+1.5 \mathrm{deg}$,

- $\quad \mathrm{Fn}_{\mathrm{B}}=1.8, \tau_{\mathrm{F}}=\tau_{\mathrm{A}}+2 \mathrm{deg}$,

- $\quad \mathrm{Fn}_{\mathrm{B}}=3.5, \tau_{\mathrm{F}}=\tau_{\mathrm{A}}+0.5 \mathrm{deg}$.

As explained in section 1.13.a and 1.13.b, an increase of the trim angle corresponds to an increase of the angle of attack of the wing, therefore to an increase of the aerodynamic lift. Since the increase of the trim angle, shifting the CG rearward, is bigger than increasing the wing surface $S$ or the angle $\eta$ of the same percentage, the positive effect on the resistance to weight ratio is enhanced. Vice versa, the forward shift of the CG has a negative effect.

\section{CONCLUSIONS}

The authors developed a mathematical framework to calculate the performance of a hybrid vehicle, a vehicle having a prismatic planing hull and one or more wing(s).

Using the mathematical model developed to estimate the HV equilibrium attitude across a range of speed, a parametric analysis has been conducted. The results are that:

- diminishing the longitudinal distance between the transom of the hull and the CG or
- $\quad$ increasing the surface of the wing (S) or

- increasing the angle between the wing mean aerodynamic chord and the keel $(\eta)$

lead to the resistance to weight ratio of the $\mathrm{HV}$ to diminish. In particular, the positive effect of shifting the CG rearward is more significant than increasing the surface of the wing. The increase of $\eta$ angle has the smallest positive effect.

Finally, following the approach of Irodov [5] and Staufenbiel [10] for WIGe vehicles, a criterion to estimate the static stability of HV has been developed.

\section{REFERENCES}

1. MEYER, J. R., CLARK, D. J., ELLSWORTH, W. M., 'The Quest for Speed at Sea', Naval Surface Center, Carderock Division, Technical Digest, 2004

2. DOCTORS, L. J., 'Analysis of the Efficiency of an Ekranocat: A Very High Speed Catamaran with Aerodynamic Alleviation', RINA, International Conference on Wing in Ground Effect Craft (WIGs '97), 1997

3. COLLU, M., PATEL, M. H., TRARIEUX, F., 'A Unified Mathematical Model for High Speed Hybrid (Air and Water-borne) Vehicles', 2nd International Conference on Marine Research and Transportation (ICMRT 07), 2007

4. KOLYZAEV, B., ZHUKOV, V., MASKALIK, A., 'Ekranoplans, Peculiarity of the theory and design', Saint Petersburg Sudostroyeniye, 2000

5. IRODOV, R. D., 'WIG Longitudinal Stability Criteria (Kriterii prodol'noy ustoychivosti ekranoplana)', TsAGI (Central Institute of Aerohydrodynamics im. N. Ye. Zhukovskij), 1970

6. ROZHDESTVENSKY, K. V., 'Ekranoplans - the GEM's of fast water transport', Transactions of The Institute of Marine Engineer, Vol. 109, pp. 47-74, 1996

7. ROZHDESTVENSKY, K. V., Wing-in-ground effect vehicles', Progress in Aerospace Sciences, Vols. 42, pp. 211-283, 2006

8. KUMAR, P., 'Stability of Ground Effect Vehicles', Cranfield College of Aeronautics, Report Aero No. 198, 1967

9. KUMAR, P., 'On the Longitudinal Dynamic Stability of a Ground Effect Wing', Cranfield College of Aeronautics, Report Aero No. 202, 1968

10. STAUFENBIEL, R. W., BAO-TZANG, Y., 'Stability and control of ground effect aircraft in longitudinal motion (translation)', David W. Taylor Naval Ship Research and Development Center, 1977 
11. GERA, J., 'Stability and Control of Wing-InGround Effect Vehicles or Wingships', AIAA, 33rd Aerospace Sciences Meeting and Exhibit, 1995

12. HALL, I. A., 'An investigation into the flight dynamics of wing in ground effect aircraft operating in aerodynamic flight', Cranfield University, MSc Thesis, 1994

13. SAVITSKY, D., 'Hydrodynamic Design of Planing Hulls', Journal of Marine Technology, Vol. 1, pp. 71-95, 1964

14. MARTIN, M., 'Theoretical Determination of Porpoising Instability of High-Speed Planing Boats', Journal of Ship Research, Vol. 22, pp. 32-53, 1978

15. SAVITSKY, D., De LORME, M. F., DATLA, R., 'Inclusion of Whisker Spray Drag in Performance Prediction Method for High-Speed Planing Hulls', Marine Technology, Vol. 44, pp. 35-56, 2007

16. SHIPPS, P. R., 'Hybrid ram-wing/planing craft today's raceboats, tomorrow's outlook', AIAA/SNAME Advanced Marine Vehicles Conference, 1976

17. WARD, T.M., GOELZER, H. F., COOK, P. M., 'Design and performance of the ram wing planing craft KUDU II', AIAA/SNAME Advanced Marine Vehicles Conferences, 1978

18. KALLIO, J. A., 'Results of full scale trials on two high speed planing craft (KUDU II and KAAMA)', David W. Taylor Naval Ship Research and Development Center, DTNSRDC/SPD-0847-01, 1978

19. RUSSELL, J. D., 'Secrets of Tunnel Boat Design', AeroMarine Research, ISBN 189493330-3, 2002

20. DOCTORS, L., 'Hydrodynamics of High-Speed Small Craft', University of Michigan, 1985

21. DELHAYE, H., 'An Investigation into the Longitudinal Stability of Wing In Ground effect vehicles', MSc thesis, Cranfield University, 1997

22. CHUN, H. H., CHANG, C. H., 'Longitudinal stability and dynamic motion of a small passenger WIG craft', Ocean Engineering, Vol. 29, pp.1145-1162, 2002

23. FALTINSEN, O. M., 'Hydrodynamics of HighSpeed Vehicles', Cambridge University Press, 2005

24. CARTER, A. W., Effect of Ground Proximity on the Aerodynamic Characteristics of Aspect-Ratio-1 Airfoils With and WIthout End Plates', NASA

Technical Note, Vol. D-970, 1960

\section{AUTHORS BIOGRAPHY}

Maurizio Collu GMRINA graduated in Aerospace Engineering (mark 100/100) in Milan, Italy. He then joined Cranfield University and the Offshore
Engineering \& Naval Architecture Group as a $\mathrm{PhD}$ researcher under the supervision of Prof. Minoo Patel. The project is a preliminary study on Marine Unmanned Aerial Vehicles (MUAVs) for British Aerospace. He is responsible for the study of the dynamics of this HV, a hybrid vehicle between a wing in ground effect vehicle and a high speed marine vehicle. He presented a paper on the dynamic stability of $\mathrm{HV}$ at the International Conference on Marine Research and Transportation 2007.

$\begin{array}{lccc}\text { Prof. Minoo } & \text { Patel FREng, BSc, PhD, CEng, } \\ \text { FIMechE, } & \text { FRINA, } & \text { Hon } & \text { RCNC }\end{array}$ After graduation from a PhD in 1973, Minoo Patel started his career as an aerodynamicist and subsequently worked on the determination of aerodynamic gust loads on aircraft wings before opting for a change of career to offshore mechanics. He established a large group working in this field and has an output of over 110 research papers, 2 books and 8 Patents. His current research and work for industry is on combined air and water borne high speed vehicles and on aspects of maritime Unmanned Air and Surface Vehicles.

Dr Florent Trarieux is a lecturer at Cranfield University in the Offshore Engineering \& Naval Architecture Group. His interest in High Speed Marine Vehicles leads him to launch an innovative research program at Cranfield in three main areas: coupled aerohydrodynamics, novel concept design and control of hybrid vehicles at the air-water interface. 


\begin{tabular}{|c|c|c|c|c|c|c|c|c|}
\hline \multirow{2}{*}{\multicolumn{2}{|c|}{$\begin{array}{l}\text { VEHICLE } \\
\text { CHARACTERISTICS }\end{array}$}} & \multirow{3}{*}{$\begin{array}{c}\text { BASIC } \\
\text { CONFIG. } \\
\text { conf. A }\end{array}$} & \multicolumn{6}{|c|}{ COMPARISON CONFIGURATIONS } \\
\hline & & & \multicolumn{2}{|c|}{ Wing area analysis } & \multicolumn{2}{|c|}{$\eta$ analysis } & \multicolumn{2}{|c|}{ Icg analysis } \\
\hline Geometry & unit & & conf. B & conf. C & conf. D & conf. E & conf. F & conf. G \\
\hline \multicolumn{9}{|l|}{ Propulsion } \\
\hline$(\xi, \zeta) \mathrm{TP}$ & {$[\mathrm{m}]$} & \multicolumn{7}{|c|}{$(0,0) \mathrm{m}$} \\
\hline$\varepsilon[\mathrm{deg}]$ & {$[\mathrm{deg}]$} & \multicolumn{7}{|c|}{$12 \mathrm{deg}$} \\
\hline \multicolumn{9}{|c|}{ Aerodynamic surface (one wing) } \\
\hline mac & {$[\mathrm{m}]$} & 14.1 & $\mathbf{0}$ & 20 & \multicolumn{2}{|c|}{14.1} & \multicolumn{2}{|c|}{14.1} \\
\hline $\mathrm{S}$ & {$\left[\mathrm{m}^{2}\right]$} & 200 & $\mathbf{0}$ & 400 & \multicolumn{2}{|c|}{200} & \multicolumn{2}{|c|}{200} \\
\hline$\eta$ & [deg] & 10 & 1 & 10 & $\mathbf{0}$ & 5 & \multicolumn{2}{|c|}{10} \\
\hline$(\xi, \zeta) \mathrm{AC}_{1}$ & {$[\mathrm{~m}]$} & $(20,0)$ & 1 & $(20,0)$ & \multicolumn{2}{|c|}{$(20,0)$} & $(21.3,0)$ & $(18.7,0)$ \\
\hline profile & $T$ & G.M. 21 & 1 & G. M. 21 & \multicolumn{2}{|c|}{ G.M. 21} & \multicolumn{2}{|c|}{ G.M. 21} \\
\hline \multicolumn{9}{|c|}{ Hydrodynamic surface (prismatic planing hull) } \\
\hline beam & {$[\mathrm{m}]$} & \multicolumn{7}{|c|}{$5.547 \mathrm{~m}$} \\
\hline$\beta$ (deadrise) & [deg] & \multicolumn{7}{|c|}{$14 \mathrm{deg}$} \\
\hline $\mathrm{A}_{\mathrm{h}}$ (frontal area) & {$\left[\mathrm{m}^{2}\right]$} & \multicolumn{7}{|c|}{$20.067 \mathrm{~m}^{2}$} \\
\hline \multicolumn{9}{|l|}{ Inertial } \\
\hline lcg (from transom) & {$[\mathrm{m}]$} & & & 8.656 & & & $\begin{array}{l}\mathbf{7 . 3 5 8} \\
(-15 \%)\end{array}$ & $\begin{array}{l}\mathbf{9 . 9 5 4} \\
(+15 \%)\end{array}$ \\
\hline vcg (from keel) & {$[\mathrm{m}]$} & \multicolumn{7}{|c|}{1.387} \\
\hline mass & {$[\mathrm{kg}]$} & \multicolumn{7}{|c|}{$52160 \mathrm{~kg}$} \\
\hline
\end{tabular}

Table 1: Characteristics of the analyzed configurations

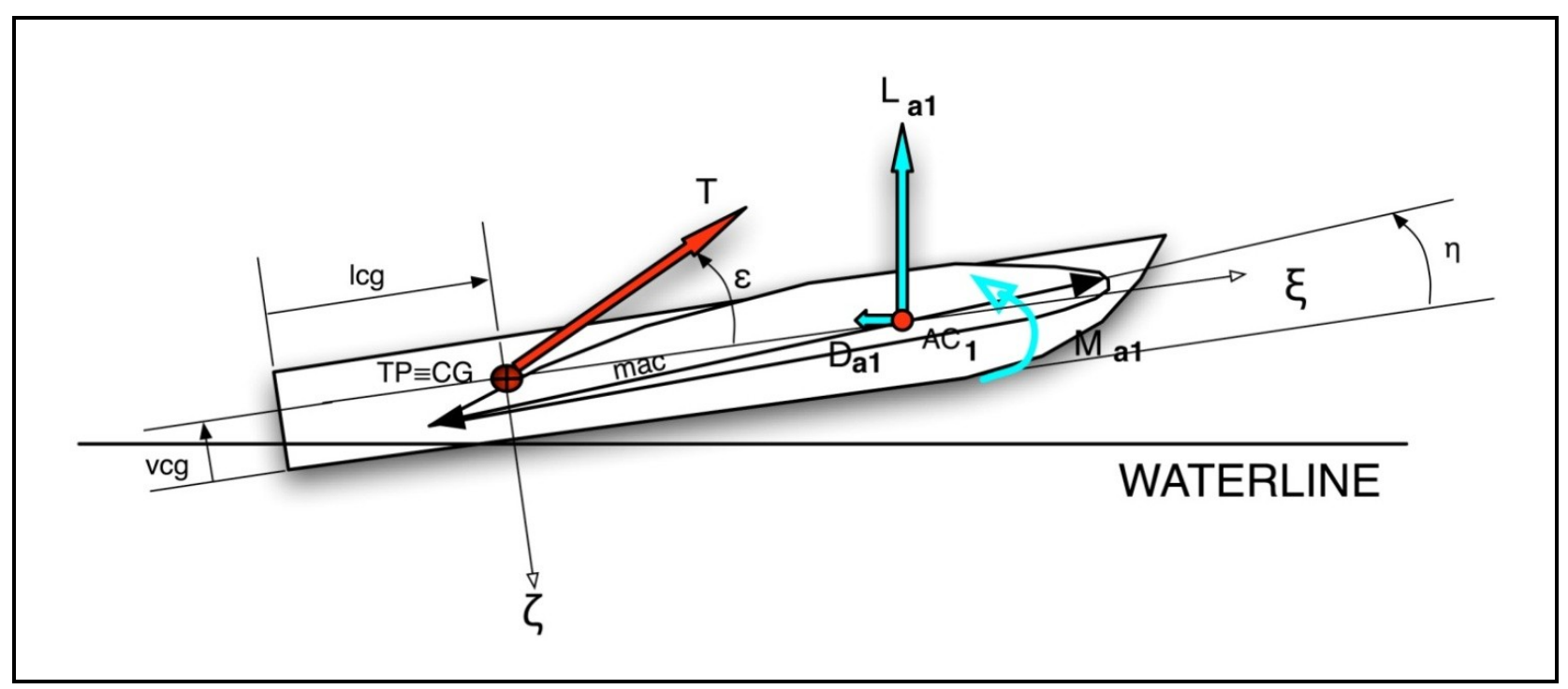

Figure 1: characteristics of the analyzed configurations 


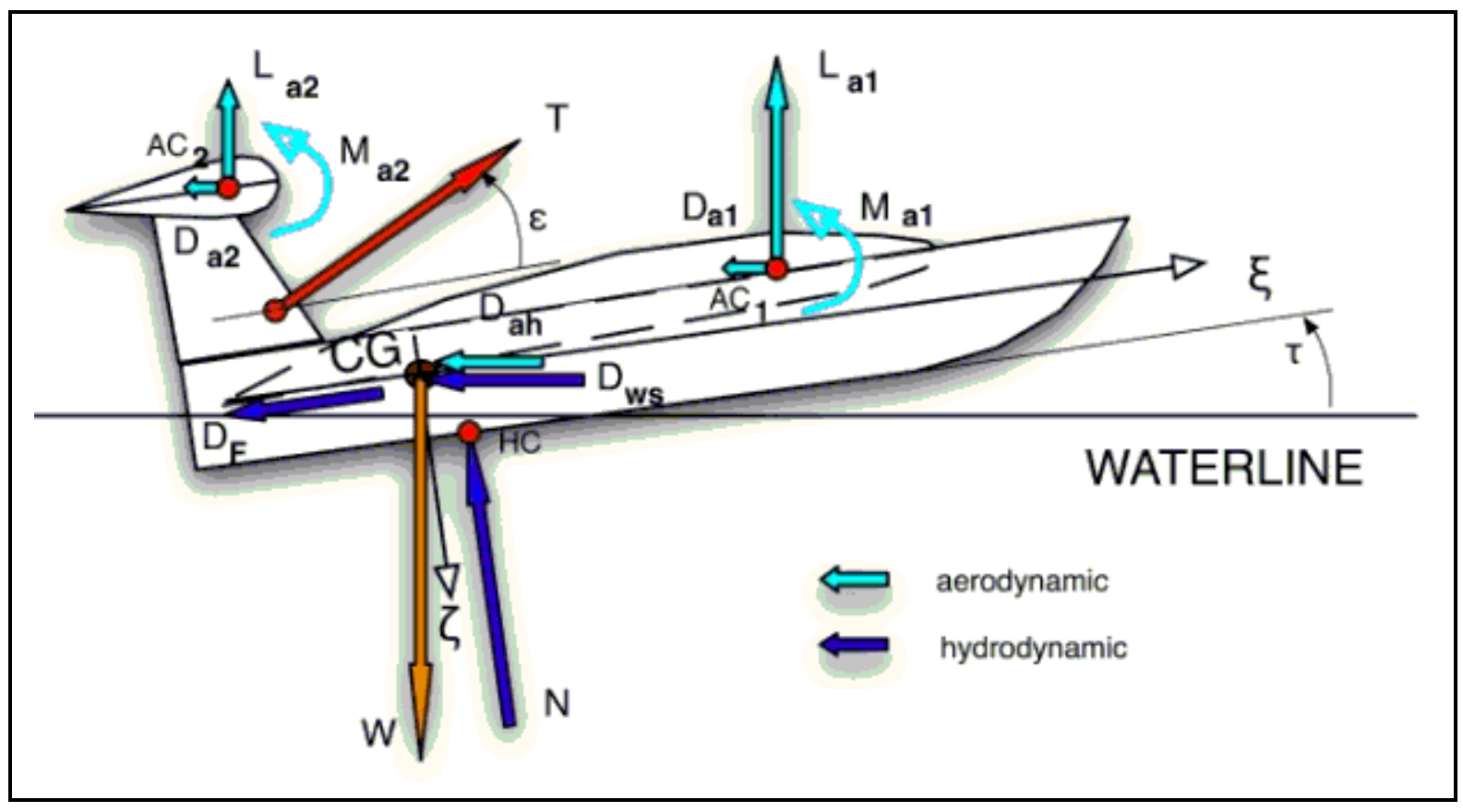

Figure 2: forces and moments acting on the hybrid vehicle

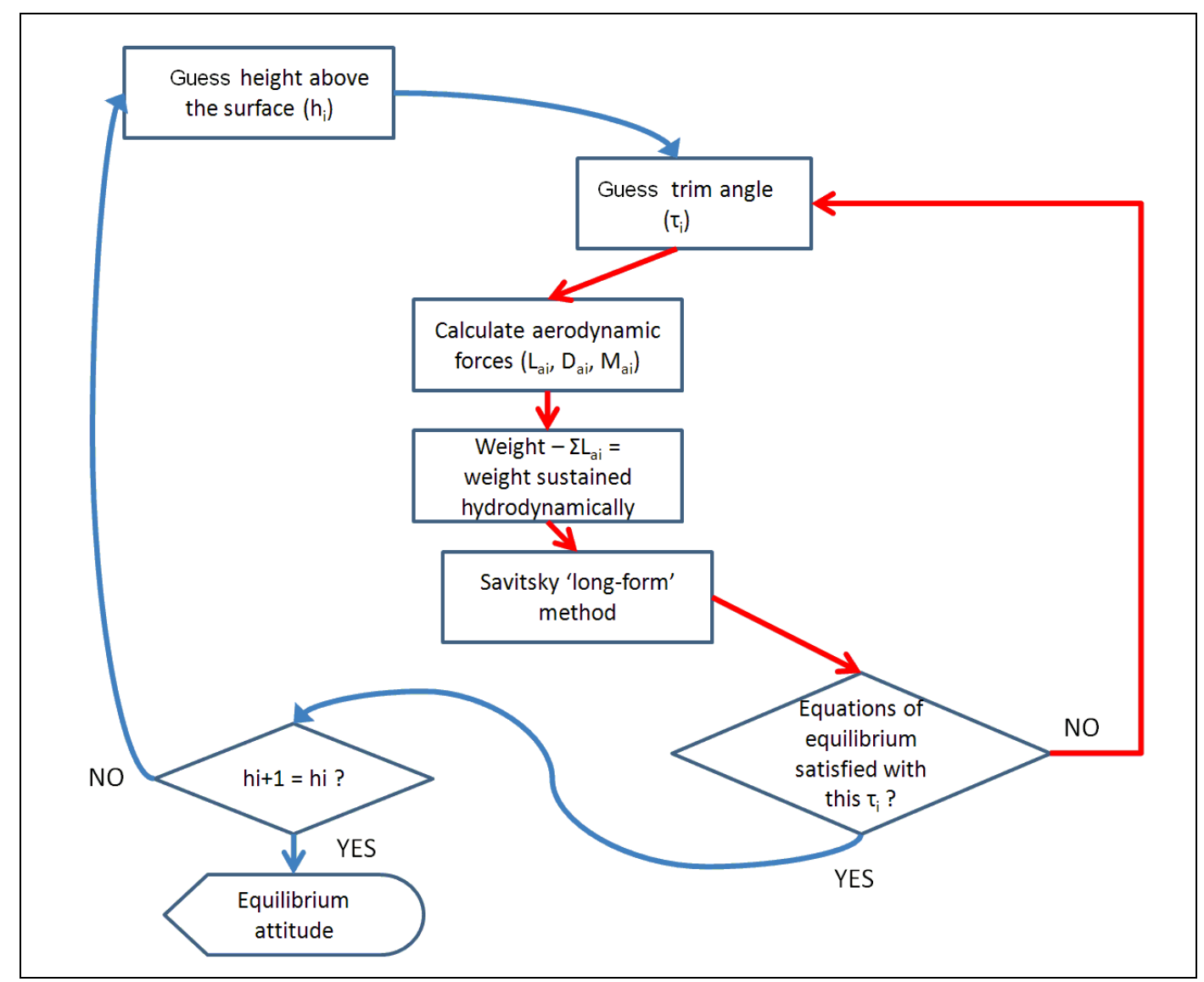

Figure 3: flow chart of the method to find the equilibrium attitude of the HV 

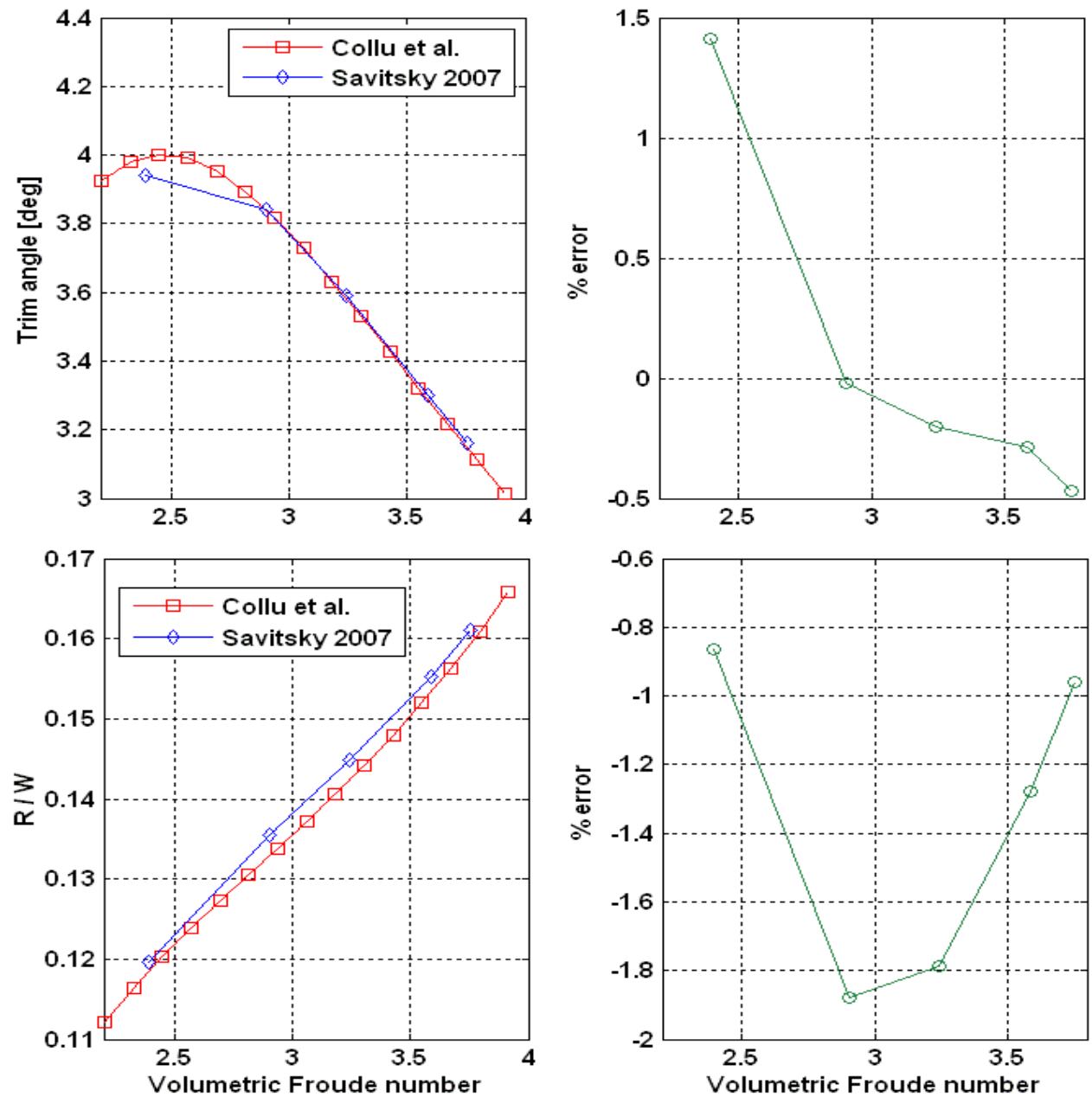

Figure 4: Savitsky 2007 (15) vs. Collu et al. - Trim angle and Resistance-to-Weight ratio 


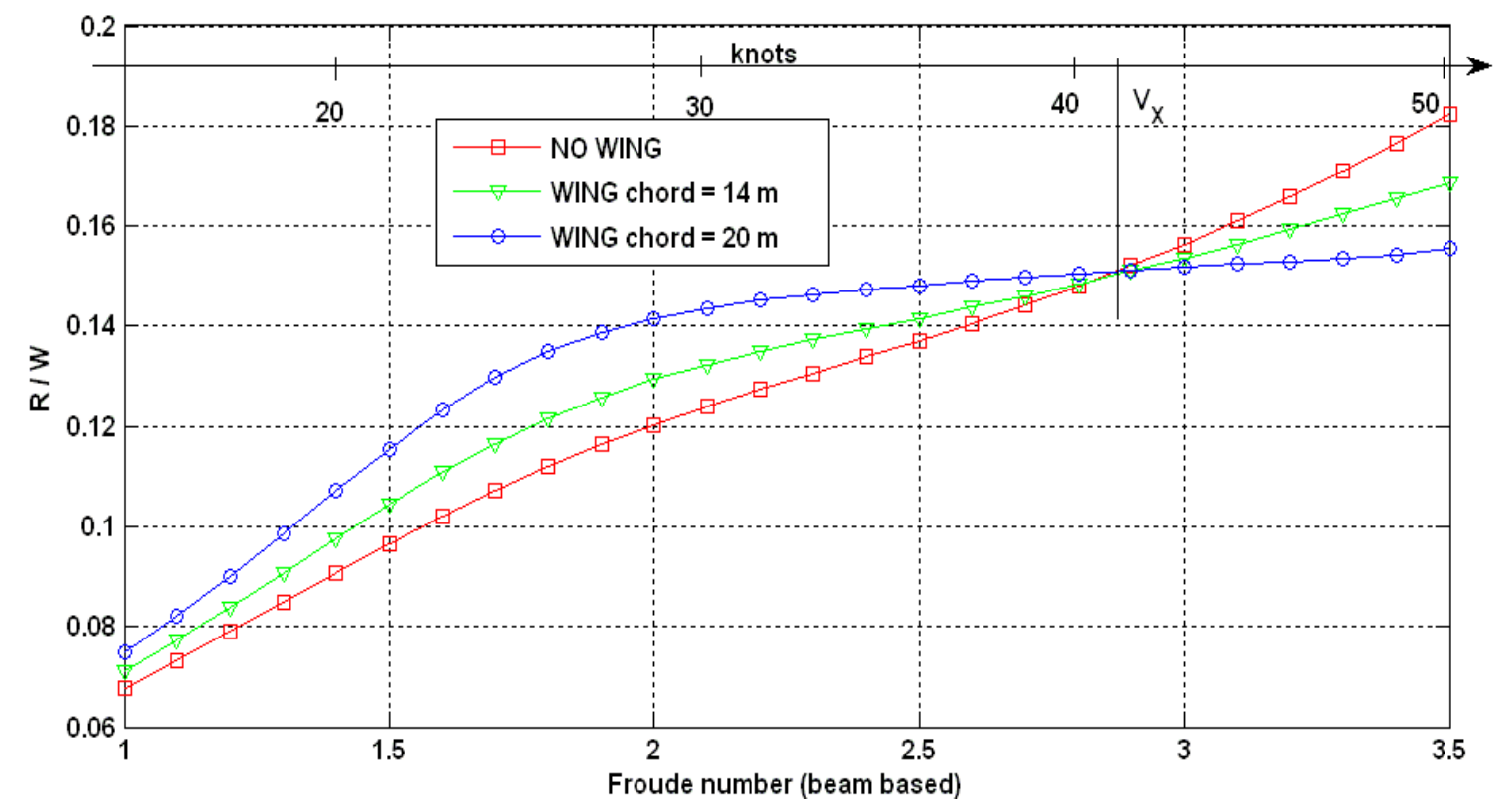

Figure 5: influence of the wing area considering the Resistance-to-Weight ratio

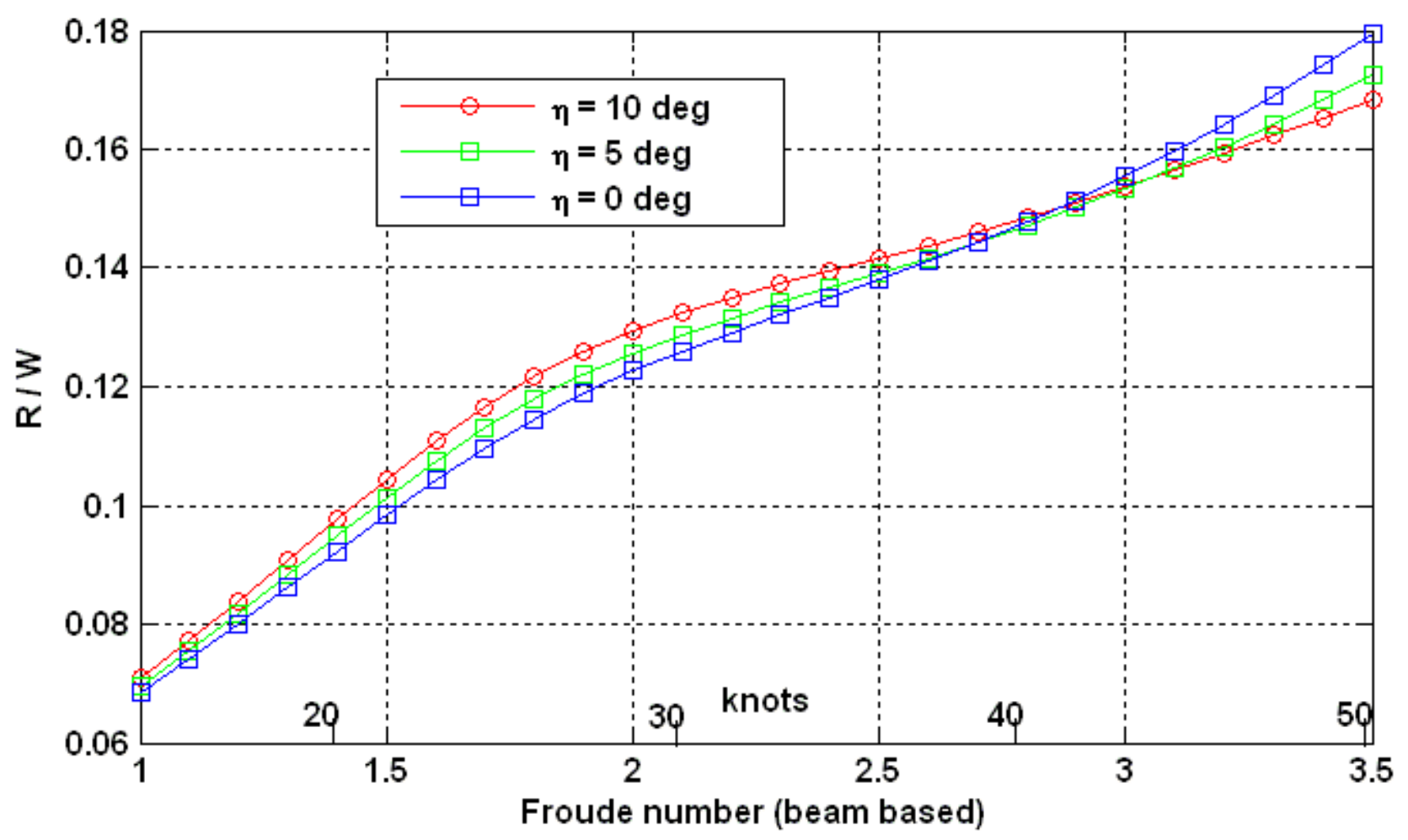

Figure 6: influence of $\eta$ considering the Resistance-to-Weight ratio 


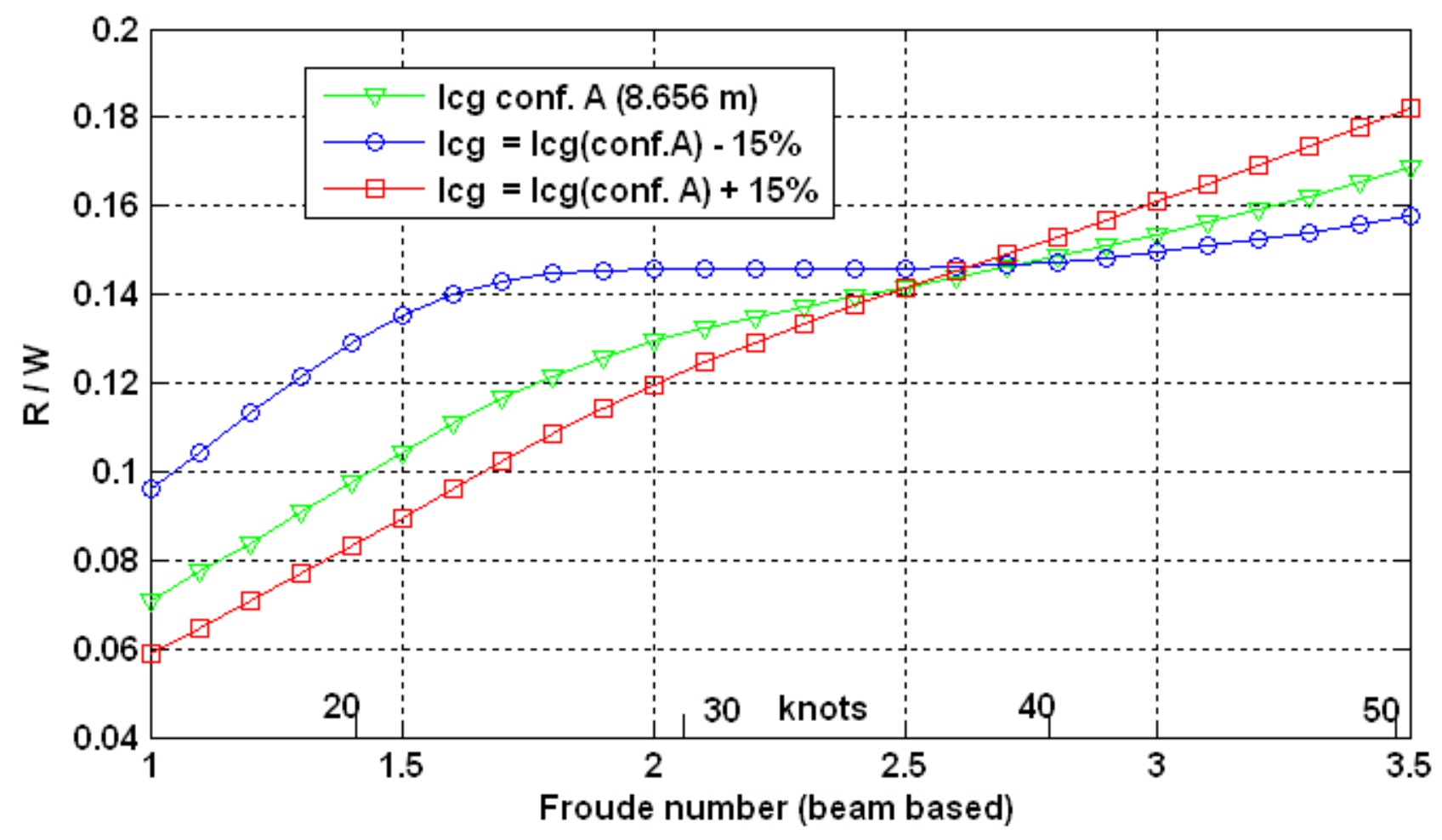

Figure 7: Influence of the longitudinal position of CG considering the Resistance-to-Weight ratio 